\title{
A Corpus Stylistic Analysis of Speech and Thought Presentation in James Joyce's Dubliners
}

\author{
Muhammad Ajmal \\ $\mathrm{PhD}$ Researcher \\ International Islamic University, Islamabad-Pakistan \\ Prof. Dr. Ayaz Afsar \\ Dean Department of English Language and Literature, \\ International Islamic University, Islamabad-Pakistan
}

\begin{abstract}
The present article attempts to analyze the interaction between categories of speech and thought in James Joyce's Dubliners quantitatively and qualitatively by applying Leech and Short Model (1981/2007). Excerpts of 2000word length have been randomly selected and manually tagged to have the accurate annotation keeping in mind the contextual potential to recognize discourse categories in Joyce fiction and then corpus software AntConc (Laurence Anthony 2018) was used to get quantitative results. The present study is grounded within three separate but interrelated disciplines: Stylistics, Discourse Analysis, and Narratology. It is difficult to imagine an example of a narrative that does not contain a reference to or a quotation of someone's speech or thoughts. To a large extent, the way we perceive a story depends upon the ways discourse is presented. This is something hard to demarcate the boundaries between them as the various modes have the potential to slip into one another. Special emphasis is given to variations between the three modes as well as to the instances of ambiguity created by their interplay. The article also compares findings with those described in Semino and Short (2004) for their corpus of 20th-century narrative fiction.
\end{abstract}

Keywords:Corpus Stylistics, speech presentation, thought presentation, Leech and Short Model

DOI: $10.7176 / \mathrm{JLLL} / 81-05$

Publication date:August $31^{\text {st }} 2021$

\section{Introduction}

The present paper attempts to analyze the interaction between categories of speech and thought in James Joyce's fiction quantitatively and qualitatively by applying Leech and Short Model (1981/2007). The present study is grounded within three separate but interrelated disciplines: Stylistics, Discourse Analysis, and Narratology. Stylistics is concerned with the systematic analysis of style in language (McIntyre, 2006). Discourse Analysis deals with the ways in which language is used in texts and contexts (Simpson, 1993). Narratology studies the structure and function of narrative. Works in stylistics have in-depth analysis of literary texts and how the selection and organization of speech impact the factual and the fictional texts. Stylistics and narratology (Cohn, 1978; Kenan, 1983; Fludernik, 1993; Semino, 2004; Leech \& Short, 2007) explain that notions of speech and thought presentation are an important aspects of the narrative discourse related to the relationship between the characters' and narrator's speech. Having access to the three speeches depends on how much the narrator wants to be distanced in the manner of representation.

The aim of this study is threefold. First, it aims to identify the most distinguished varieties of speech and thought presentation used by James Joyce and how these varieties interact to shape fictional reality. Second, it clarifies how the blurred boundaries and fuzzy-edged nature of modes of speech and thought presentation can be manifested in James Joyce short stories. Third, it aims to investigate how the categories of speech and thought presentation serve to clarify the controversial issue of viewpoint as well as to identify the writer's position.

Busse (2017:01) in the very first sentence of her book addresses the importance of the phenomenon of speech and thought in a literary text and suggests this as an integral part for narrative progression and discourse presentation. Bernaerts (2010: 283) also stresses the importance of speech and thought by stating, "the interpretation and evaluation of a narrative is affected by the particular interplay between a narrator's and characters' speech and thought".

Hence, the issue in the heart of this study is to investigate how modes of speech and thought presentation are interacted in James Joyce short stories and make the text coherent with all its ambiguities of three modes of discourse.

Semino and Short (2004) assert that doing a corpus-based work is highly quantitative in nature, but this matter of fact does not mean that qualitative analysis should be excluded. On the contrary, if both are combined they help to reach to a higher degree of understanding of literary works or any other selected data.

One of the most widely accepted frameworks for the description of the phenomenon in this tradition is Leech and Short's (1981) model. Leech and Short proposed parallel scales of speech and thought presentation 
categories for the novel, arranged on a cline of different degrees of apparent narratorial interference. As one moves across the cline from left to right, the categories reflect an increasing lack of apparent narrator 'control' of the report. This results at the extreme right of the scale in the categories of 'free direct' speech or thought, the effect of which is to suggest that what we have in these instances are the words and thoughts of the characters themselves, with no narratorial intervention at all.
NV
NRSA
IS
FIS
DS
FDS
NI
NRTA
IT
FIT
DT
FDT

Leech and Short (2007) draw a cline of narratorial interference for modes of speech presentation which is illustrated in Figure 2 below:

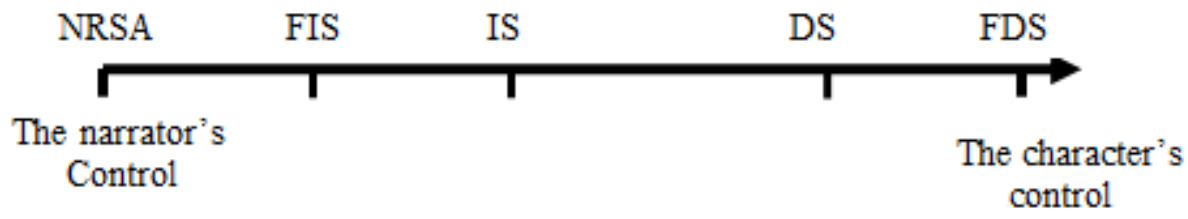

The narrator enjoys absolute authority in a narrative text to decide how characters and events are presented and this provides opportunity for interpretation of the work as a whole. From the outset, it should be stated that there are problems inherent in delineating discourse so precisely into clearly defined modes. This is something that Leech and Short themselves identify when they discuss how the various modes they propose are easily able to slip into one another, with the boundaries between them at times hard to demarcate.

The narrator's interference is indicated through the position of each category of speech presentation in the cline, where DS is the norm and these indicate the absence of the narrator's control. Any movement leftwards from DS includes the interference of the narrator, whereas any movement rightwards from this mode leads to the growing absence of the narrator's intervention and same applies to categories of writing and thought presentation. This results at the extreme right of the scale in the categories of 'free direct' speech or thought, the effect of which is to suggest that what we have in these instances are the words, writing and thoughts of the characters themselves, with no narratorial intervention at all.

\section{Annotation and Methodology}

Since the researcher aimed to capture a complex and relatively 'high level' discoursal phenomenon, the analysis of which requires a considerable amount of contextual and pragmatic inferencing on the part of analysit and manual tagging becomes a must.

The annotation of a stretches of text from James Joyce's short story The Boarding Housethen looks as follows:

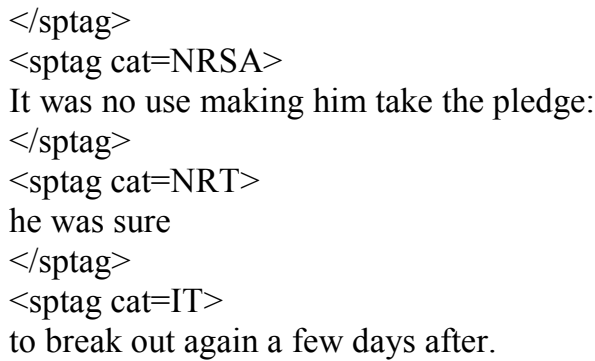

In the annotation process, ambiguous cases will be accounted for in the speech act category tag (" $<$ sptag cat $>$ "). For example, a stretch that is ambiguous between narration and free indirect thought would be categorized as " $<$ sptag cat $=$ N-FIT $>$." An example would be:

$</$ sptag $>$

$<$ sptag cat $=$ N-FIT $>$

\subsection{Research Questions}

This article intends to address the following research questions;

1. What is the percentage of speech and thought presentation categories in the corpus of James Joyce Dubliners?

2. What are the variations and effects of speech writing and thought presentation modes and instances of ambiguity created by their interplay?

\section{General Quantitative Observations}

Table below show the percentages for the modes of discourse presentation and for narration, computed by the 
number of tags that have been allocated to the identified stretches that present the various categories of the different modes of discourse presentation. Stretches of narration are tagged separately (and include all occurrences of reporting clauses) in order to be able to compare discourse presentation with narration. Furthermore, the interplay between stretches of discourse presentation and narration is provided. Ambiguous annotations of discourse presentation which are summarized under the term "other".

In the James Joyce corpus, the total number of tags (including those tags identifying narration) amount to $1862.47 \%$ of these tags are speech presentation categories and $27 \%$ are narration tags. Thought presentation is $24 \%$ and double tags are only $2 \%$ of the total tags identified by the corpus tool where the researcher is undecided due to the ambiguity in categories.

In terms of frequency, there are large imbalances among the three modes of discourse presentation. The tags for speech presentation are by far the most frequently used.

Ttable: 3.1 Percentages of speech and thought presentation in Dubliners

\section{Distribution of Discourse Categories}

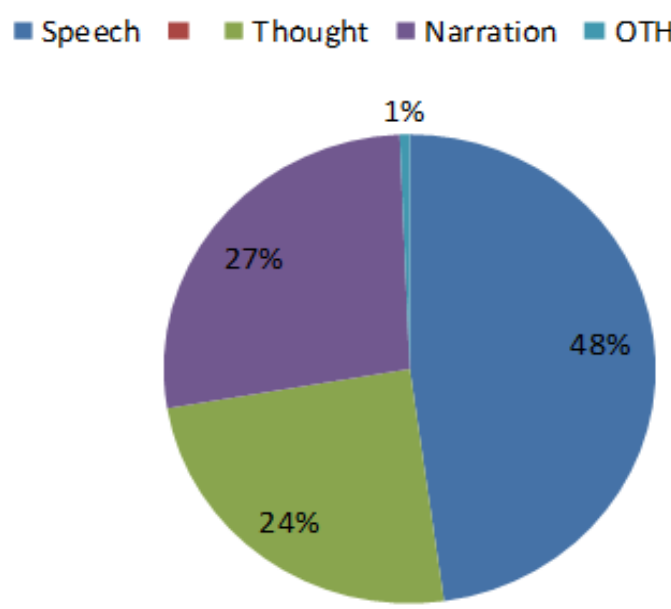

Table shows that on the speech presentation scale DS is the most frequently tagged category. DS tags also come on first position in the 20th-century fictional subcorpus tagged by Semino and Short (2004: 67). As regards thought presentation, my corpus shows a preference for narrator's report of thought act (NRTA) instances. Semino and Short (2004: 117) identify internal narration (NI) as the most frequently tagged category in their 20th century corpus, followed by FIT.

Table 3.2 - The number of occurrences and percentages of speech presentation cline in Dubliners

\section{Speech Presentation}

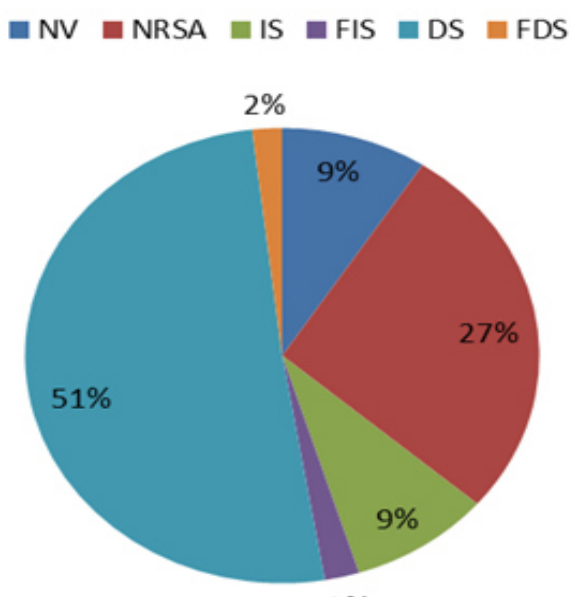

$2 \%$

The summarizing categories for speech presentation NRSA and IS, which are more towards the narrator's end of the scale, also come second and third. The margin of percentages of tags between NRSA and IS is 
significantly higher. NV, as the summary of a speech report, is on fifth position by which the tags are represented.

With a tag-percentage of $8.1 \%$ for NRSA and $7.3 \%$ for NRTA, NRSA occurs more frequently in my corpus than NRTA. Hence, it is striking that for the summarizing categories, the mean length of a tag is longer for NI and NRTA than for NV and NRSA and also more words are used, despite the fact that the number of tags for NRSA precedes those for NRTA. Although it should be stressed that tags for NT are rather few in the corpus, as are the overall numbers of words by which they are presented, it is also striking that the average length of the stretches of NT surpass that of NI and NRSA.

\subsection{Speech Presentation Categories}

\subsubsection{Narrator's Presentation of Voice (NV)}

In Dubliners by James Joyce, a narrator's representation of voice captures minimal reports of speech. It consists of some information about a speech event or indications concerning the fact that someone speaks, as in "and some of the bystanders gave advice" (Dubliners/Grace 2011 [1914]: 141). It may also point to a desired hypothetical speech event. As table above illustrates, NV occurs second-least frequently on the speech presentation scale. The number of tags identified as NV in the corpus amounts to only 160 (which constitutes $3.2 \%$ of all tags identified in the corpus).

As far as the first function is concerned, an example from Joyce's (2011 [1914]): 141) Dubliners/Grace can be used:

The manager at once began to narrate what he knew. The constable, a young man with thick immobile features, listened. He moved his head slowly to right and left and from the manager to the person on the floor, as if he feared to be the victim some delusion.

One man falls on his way and loses consciousness which makes people to gather on the spot. The crowd is eager to know the reason of that incident. The sentence provides no meaningful expression to the reader: "The manager at once began to narrate what he knew". The locutionary force of this utterance is then re-expressed by the third-person narrator (who is also the focalizer). The stretch of NV establishes the parallel nature between the words uttered and what is actually done. As such, the narrative and discoursal framework become more complex and ask the reader to establish a multi-faceted (if not realistic) scene of processing words and deeds synchronously.

Another example of NV's first function (that is, narrative progression through encapsulation of progression) is provided in the following chunk of words from Joyce's (2011 [1914) The Sisters:

As I walked along in the sun I remembered old Cotter's words and tried to remember what had happened afterwards in the dream. I remembered that I had noticed long velvet curtains and a swinging lamp of antique fashion. I felt that I had been very far away, in some land where the customs were strange - in Persia, I thought.... But I could not remember the end of the dream. (Dubliners/The Sisters2011 [1914]: 05).

The stretch of "I remembered old Cotter's words" summarizes the words uttered by the old Cotter, but at the same time foregrounds - almost like a stage direction - the simultaneity of the Cotter's paralinguistic activities accompanying his words.

Sinclair's (2004) emphasis on 'trusting the text', as described in previous chapters, is not simply realized by encapsulation but also by means of prospection. Sinclair states that prospection functions by foreshadowing semantically, syntactically, and pragmatically what is about to be said. In Joyce's (2011 [1914]) Araby, the boy explains the past spent with mirth and carelessness and this is prospected through a fixed expression as NV in "our shouts echoed in the silent streets:"

The stretch of NV "He spoke without listening to the speech of his companions." links the discourse presentation mode of speaking with that of thinking in the previous stretch of a rare case of a summarizing NT "He knew the inner side of all affairs and was fond of delivering final judgments." He is portrayed as a social eremite who is able to criticize the superficial establishment of phatic communication and politeness with strangers and severely loathes the atmosphere as well as the life of others. But it is only revealed to the reader as a private reflection. The speech event is described as social, and additional paralinguistic information is given by means of the adjective "stately," which describes the pride and arrogance of his voice.

\subsubsection{Narrator's Presentation of Speech Acts (NRSA)}

NRSA represents the third largest category of discourse presentation in my corpus and NRSA is on fourth position in the corpus overall. An example to illustrate this is "and talking animatedly to his mother who nodded her head gravely and slowly in acquiescence" (the Dead2011 [1914]: 182). Aunt Julia and Freddy Malins have nack for singing and they heard the singer with interest and passion, who had listened with his head perched sideways to hear her better, was still applauding when everyone else had ceased" (The Dead2011 [1914]: 182). The stretch of "and talking animatedly to his mother who nodded her head gravely and slowly in acquiescence" furthers the progression of the narrative by enticing the reader to find out what the conversation will be about. At 
the same time, this stretch serves to create tension and to satisfy readers' curiosity concerning revelations about romantic affairs between the characters.

In the following example from Joyce's (2011 [1914]: 06) The Sisters, the narrator's paralinguistic descriptions of visiting the dead body by the sisters have to be seen in interaction with the reporting of speech in NRSA in the stretch "began to beckon:"

At the first landing she stopped and beckoned us forward encouragingly towards the open door of the dead-room. My aunt went in and the old woman, seeing that I hesitated to enter, began to beckon to me again repeatedly with her hand. I went in on tiptoe. The room through the lace end of the blind was suffused with dusky golden light amid which the candles looked like pale thin flames. He had been coffined. (Dubliners/The Sisters 2011 [1914]: 06).

Two sisters are led to the place where dead body was placed. The phrase "began to beckon to me again repeatedly with her hand" shows the gravity of the event and silence is observed in respect of the dead body in coffin. The reader is mentally prepared after reading the phrase "began to becon to me" is used as means to progress the narrative.A stretch of NRSA in "I had never spoken to her, except for a few casual words" summarizes what has been presented to the reader as IS or DS: I had never spoken to her, except for a few casual words, and yet her name was like a summons to all my foolish blood. (Dubliners/Araby2011 [1914]: 21).

\subsubsection{Indirect Speech (IS)}

The following example from Joyce's Clay(2011 [1914]) can be mentioned here in relation to IS:

Maria superintended the distribution of the barmbrack and saw that every woman got her four slices. There was a great deal of laughing and joking during the meal. Lizzie Fleming said Maria was sure to get the ring and, though Fleming had said that for so many Hallow Eves, Maria had to laugh and say she didn't want any ring or man either; and when she laughed her grey-green eyes sparkled with disappointed shyness and the tip of her nose nearly met the tip of her chin. Then Ginger Mooney lifted her mug of tea and proposed Maria's health while all the other women clattered with their mugs on the table, and said she was sorry she hadn't a sup of porter to drink it in. And Maria laughed again till the tip of her nose nearly met the tip of her chin and till her minute body nearly shook itself asunder because she knew that Mooney meant well though, of course, she had the notions of a common woman. (Dubliners/Clay 2011 [1914]: 91).

In this example, Miss Maria with other ladies is at the supper. More importantly, the IS stretch "Lizzie Fleming said Maria was sure to get the ring and, though Fleming had said that for so many Hallow Eves" serves a crucial function. The narrator appears to characterize Miss Maria as a 'flat character' incapable of producing substantial contributions and simply sticking to reporting clauses which prospect a summarizing function.

\subsubsection{Free Indirect Speech (FIS)}

Despite the low number of FIS tags, some qualitative observations are, nevertheless, necessary as they can help identify some seemingly repetitive features of FIS in 19th-century discourse. In the 19th-century corpus, the marker of freeness, that is the grammatical independence of the reported clause, is one reliable criterion. In the already quoted example from Joyce's (2011 [1914]) Clay, Miss Maria's conversation is reported in FIS in "What a nice evening they would have, all the children singing!" and "Only she hoped that Joe wouldn't come in drunk:"

What a nice evening they would have, all the children singing! Only she hoped that Joe wouldn't come in drunk. He was so different when he took any drink. Often he had wanted her to go and live with them;-but she would have felt herself in the way (though Joe's wife was ever so nice with her) and she had become accustomed to the life of the laundry. (Dubliners/Clay 2011 [1914] : 90).

Further revealing is writing the letter which serves to distance the narrator from Emma's words and at the same time to ironically exaggerate Mrs. Gabrael's emotional turmoil.

Stretches of FIS are often prepared or projected by means of other speech presentation modes as can be seen in the next two examples from Joyce's (2011 [1914]) Clay. In the FIS stretch, ("so full of pleasant talk") occurs in the middle of the sentence:

Soon they were all quite merry again and Mrs. Donnelly said Maria would enter a convent before the year was out because she had got the prayer-book. Maria had never seen Joe so nice to her as he was that night, so full of pleasant talk and reminiscences. She said they were all very good to her. (Dubliners/Clay 2011 [1914]: 95).

The following stretch of "He would say" in the example of Joyce's (2011 [1914]) the Deadis embedded in Gabrael's passage of DS. The position of the reported clause before the reporting clause makes it appear to be less controlled by the narrator and, hence, a stretch of FIS.

\subsubsection{Direct Speech (DS) and Free Direct Speech (FDS)}

Direct speech and free direct speech are those strategies of discourse presentation that are closest to the character in the narratological guidance of the narrative. In addition to presenting the speech act value and the 
propositional content of the utterance, DS and FDS provide the words and grammatical structures claimed to have been used to utter the propositional content and associated speech act.

To begin with the potential functions of DS and FDS in Joyce work, I quote the following excerpt from Joyce's (2011 [1914] : 170) The Dead at length:

After a pause she asked:

'And what are goloshes, Gabriel?'

'Goloshes, Julia!' exclaimed her sister 'Goodness me, don't you know what goloshes are? You wear them over your... over your boots, Gretta, isn't it?'

'Yes,' said Mrs. Conroy. 'Guttapercha things. We both have a pair now. Gabriel says everyone wears them on the Continent.'

'O, on the Continent,' murmured Aunt Julia, nodding her head slowly.

Gabriel knitted his brows and said, as if he were slightly angered:

'It's nothing very wonderful, but Gretta thinks it very funny because she says the word reminds her of Christy Minstrels.'

'But tell me, Gabriel,' said Aunt Kate, with brisk tact. 'Of course, you've seen about the room. Gretta was saying...'

' 0 , the room is all right,' replied Gabriel. 'I've taken one in the Gresham.'

'To be sure,' said Aunt Kate, 'by far the best thing to do. And the children, Gretta, you're not anxious about them?'

'0, for one night,' said Mrs. Conroy. 'Besides, Bessie will look after them.' (Dubliners/the dead 2011 [1914] : 170).

It is useful to resume the discussion of the 'faithfulness debate' outlined in chapter 2 and to underscore my arguments against the proposals to subsume FDS under the general DS category. This exchange in the Dead between Mr. Gabriel and Mrs. Conroyon the issue ofgoloshesis point of interest and prolongs conversation. There is annual Christmas party in Dublin. Gretta and Gabriel's aunts come out of the dressing room and greet Gabriel, who is their favorite nephew. Gretta tells Kate and Julia of Gabriel's strange preference for galoshes, and he explains that they're very popular on the continent. Freddy Malins arrives and the conversation dissolves. Aunt Kate asks Gabriel to keep an eye on Freddy, as he is known to show up intoxicated. As the waltz finishes, another man, Mr. Browne, takes three younger women into the back room and serves them all strong drinks, flirting until the women lose interest. Kate and another party guest enter the room and announce it is time to pair up for the next waltz.

In the example from (Dubliners/the dead2011 [1914] : 40), the necessity to differentiate between stretches of DS and FDS also becomes obvious because - although the passage is rich in sequences of vivid and immediate FDS - the narrator's control through the insertion of reporting clauses accompanying the stretches of DS is displayed at important points in the exchange. It would follow, therefore, that narratorial presence serves functions other than simply identifying the next speaker. As with many Joycean reporting clauses, those occurring in this passage are also rich in the usage of paralinguistic information to provide the speech with an additional note of attitude.

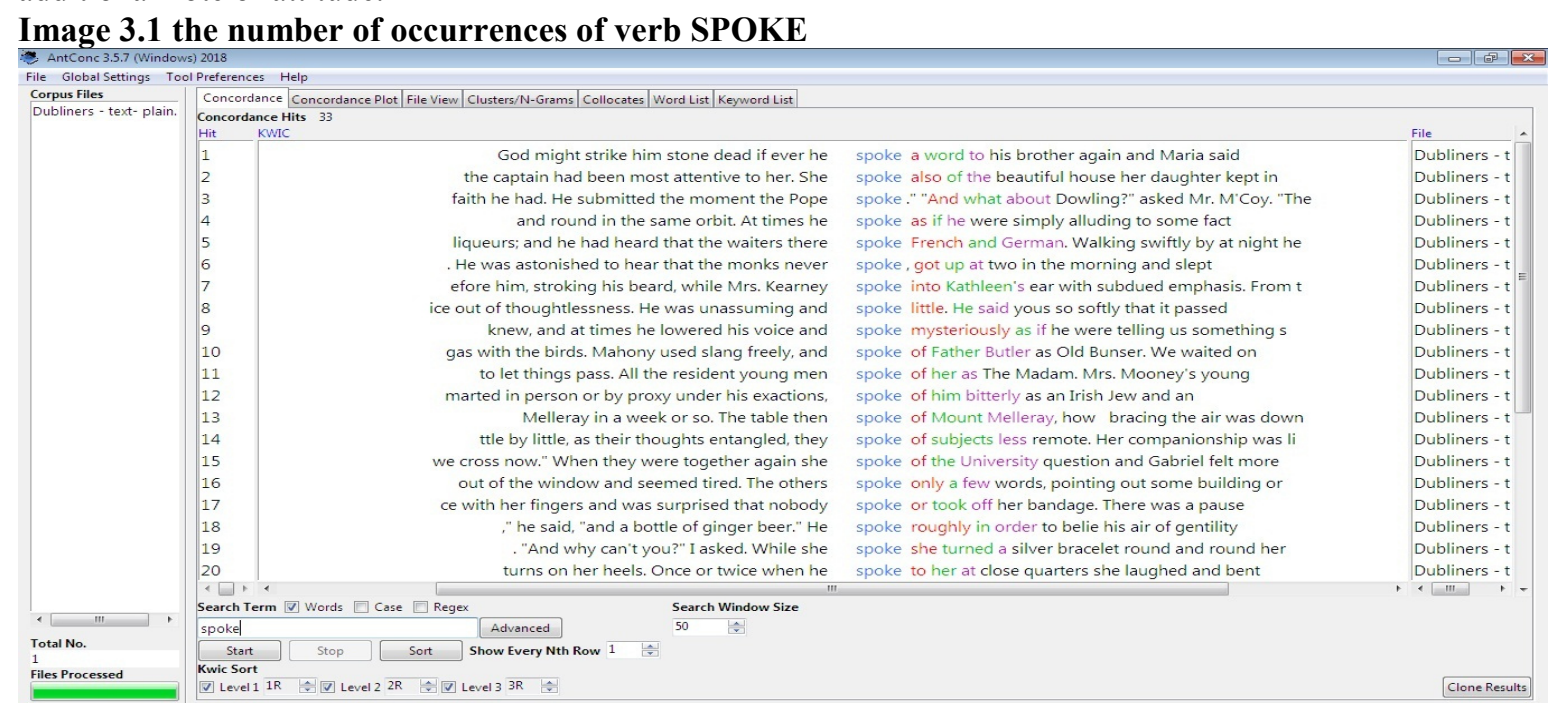

Here is given the collocation of the word 'spoke' that is essential for speaking and indicates occurance speech presentation. Quantitative results of the word show 33 tags akin to speech activity. 


\section{Thought Presentation Categories}

Table 4.1-The number of occurrences and percentages of thought presentation cline in Dubliners

\section{Thought Presentation}

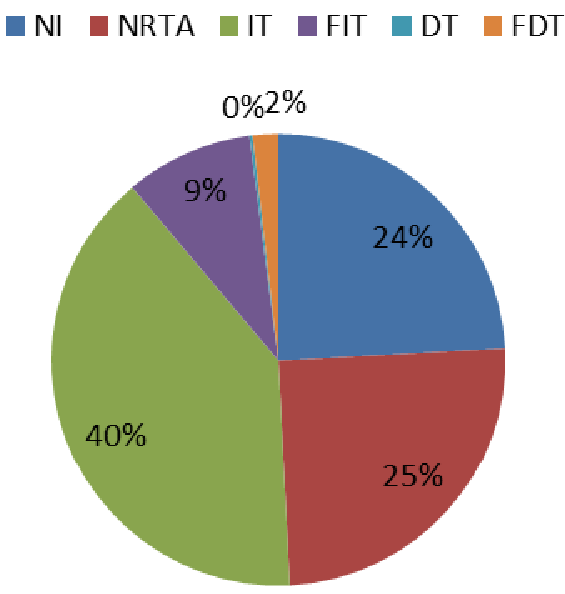

\subsection{Direct Thought (DT) and Free Direct Thought (FDT)}

I shall begin the presentation of the forms, distribution, and functions of the categories on the thought presentation scale by briefly recapitulating some of the quantitative figures.

Direct and free direct thought (DT and FDT) give access to a character's thoughts in a direct way, that is, both create the illusion that what is presented is what the character really thinks (Cohn 1978: 76). Both categories also seem to turn cognitive activities into words and foreground the impression that what is presented is a highly conscious affair. It seems that the style of thought presentation narrators in my corpus favors more complex and subtle summarizing modes of thought presentation, like NI or NRTA, or, as we have seen, lexically highly elaborate stretches of FIT.

Despite their low number of tags, DT and FDT are multifunctional in 19th-century writing. For instance, a character might wish to present their opinion in speech but may not feel to be able to do so because of social constraints; if that is the case, DT or FDT still allow the reader to partake with the character's real attitudes, feelings, or opinions on whatever issue they cannot openly verbalize.

DT and FDT are also used when the narrator explicitly creates some discrepancy between what is presented in speech and what is presented in thought, sometimes with the character reflecting on a sudden realization. To illustrate this, an incident from Joyce's Dubliners/Araby (2011 [1914] : 26) The final lines can be quoted: "Gazing up into the darkness I saw myself as a creature driven and derided by vanity; and my eyes burned with anguish and anger." (Dubliners/Araby (2011 [1914] : 26)), where the boy mentally expresses his anger for being immature to buy a gift for his beloved without having money.

FDT appears as more vivid and the reader feels closer to the character's inner consciousness. The reporting verbs used to introduce DT are not restricted to the verb think; in fact, we find an ample variety of verb phrases, such as saw myself as a creature,observe to herself, the souls of each other cried out, his eyes added, cried his soul, or said to oneself. All these verb phrases fall within the category of verbs of communication; however, they are used reflexively in my corpus to account for the fact that the activities presented are cognitive and take place in the focalizer's mind. Besides, only a clarifying reporting clause often illustrates the switch from speech to thought presentation. Consider, for instance, the following example from Joyce's A Painful Case:

His soul's companion! He thought of the hobbling wretches whom he had seen carrying cans and bottles to be filled by the barman. Just God, what an end! (Dubliners/A Painful Case2011 [1914] : 105).

The stretch is preceded by a reporting clause (not quoted) which contains the perception verb think. Because of that, the whole stretch could be considered an example of DT. Yet, the expressive nature of the both admiring but also sarcastic expression from Mr. Duffy "Just God, what an end!" may also serve as an example of FDT.

\subsection{Free Indirect Thought (FIT)}

The FIT category is situated in fourth position of the categories on the thought presentation scale in my 19thcentury data. 266 tags, i.e. $3.7 \%$ of all tags, are stretches of FIT. (This amounts to $17.4 \%$ of all categories on the thought presentation scale.) 
The same holds true for interjections or exclamations, lexically realized as oh, god help me, yes, alas, or no, which frequently occur in FIT and add to the emotional intensity that is transferred by FIT. For example, in Joyce's (2011 [1914]) A Painful Case, Mrs. Sinico reflects on absence of people in the theatre. The reader experiences her relief through the presentation of her thoughts in FIT: "What a pity there is such a poor house tonight! It's so hard on people to have to sing to empty benches." (Dubliners/A Painful Case 1985 [1816]: 99). Furthermore, non-finite infinitival constructions of the exclamatory kind as in "to sit down and eat their suppers" (Joyce 1985 [1817]: 196) is characteristic of the FIT. Here is a correlation with the linguistic realization of stretches of IT, where we often find the same structure, but where that stretch is followed by a reporting clause. Exclamations are often elliptic and consist just of a repetition of a noun phrase. But they may also be realized by complete sentences, and are also very characteristic of FIT in Joyce narrative fiction. Here is an example from Joyce's (2011 [1914]) Eveline that abounds in the use of exclamatory utterances representing the agitation of Eveline's mind:

She had consented to go away, to leave her home. Was that wise? She tried to weigh each side of the question. In her home anyway she had shelter and food; she had those whom she had known all her life about her. O course she had to work hard, both in the house and at business. What would they say of her in the Stores when they found out that she had run away with a fellow? Say she was a fool, perhaps; and her place would be filled up by advertisement. (Dubliners/Eveline 2011 [1914] : 28).

This underlines Eveline's thinking process but also stresses the importance she places on the 'her old father' and her role in making home a safe haven for old father. These constructions are usually typical of spoken language although in FIT instances they seem to reinforce the dynamic nature of the thinking process. So far, this strategy has not been identified to be diagnostic of FIT. In the next example from Joyce's (2011 [1914]) $A$ Painful Case, Mr. Duffy privately comments on Mrs. Sinico's relationship with himself after her death. His thoughts are presented in FIT (see also chapter 4.4.2.1):

The whole narrative of her death revolted him and it revolted him to think that he had ever spoken to her of what he held sacred. (Dubliners/A Painful case 2011 [1914]: 105).

The narrator informs the reader that these are Mr Duffy's thoughts through a stretch of NT in "The whole narrative of her death revolted him." Interestingly, the narrator is able to present a common human practice of thinking over the death of someone near and dear to us. This stretch is prospective, as through implicature, the reader is asked to understand (a) that there is a discrepancy between Mr. Duffy's thoughts and what he did to Mrs. Sinico, and (b) that the presentation of Mr. Duffy's thoughts at this point is highly relevant.

\subsection{Indirect Thought (IT)}

IT is an unspoken reaction to the speech of another character. Toolan (2009) does not see IT to be directly relevant to narrative progression because it shows direct narrator intervention through a reporting clause. It is less dramatic than FIT and allows for a more "mundane character deliberation" (Toolan 2009: 136). On a scale of character involvement, IT appears to be downgraded insofar as it only reports a character's thoughts through the voice of a narrator, without presentation of the actual cognitive activity. In my 19th-century corpus, the narrator's presence in IT and DT is most obvious through the reporting clauses. These appear to be highly varied and not restricted to a prototypical "he thought", or similar phrases.

Sometimes, the complementizer is left out but the sentence following the reporting clause is still IT, such as in the following: "Then she asked all the children had any of them eaten it" (Dubliners/Clay1985 [1816]: 93). In addition, a framing verb may also be part of a stretch of FIT. The framing verb then often follows the reported stretch, so that it may be difficult to decide whether the stretch is IT, FIT, or ambiguous.

The function of IT becomes more complex when the reporting clause is moved to medial or final position, because there may be a move from IT to FIT:

She stood up in a sudden impulse of terror. Escape! She must escape! Frank would save her. He would give her life, perhaps love, too. But she wanted to live. Why should she be unhappy? She had a right to happiness. Frank would take her in his arms, fold her in his arms. He would save her. (Dubliners/Eveline 2011 [1914]: 28).

The reader is presented with a stream of Eveline's thoughts in which she herself cogitates her future life with Frank. The fact that the reporting clause "I thought" does not initiate the sentence makes it more difficult to decide whether we are presented with IT or FIT, It seems that the narrator provides the reader with one linguistic clue as to the fact that Evelinee's thoughts are presented here and then moves on to the more vivid and dramatic presentation of her thoughts through FIT.

Unlike IS, the classic examples of IT do not simply fulfills a summarizing function of a character's thoughts. We rather seem to be provided with the character's real thoughts and the apparent words that verbalize them by giving the illusion of verbatim repetition of processed words is. IT is, however, less dramatic and less vivid than FIT because of the narrator's direct intervention through the reporting clause: 
He was too scrupulous always,' she said. 'The duties of the priesthood was too much for him. And then his life was, you might say, crossed.' 'Yes,' said my aunt. 'He was a disappointed man. You could see that.' . (Dubliners/the sisters 2011 [1914]: 09).

Aunt's comment is extensively stylized so that the young girl has difficulties to understand the life of the dead priest. Yet due to her subservience she does not ask gain and again. Instead, the narrator informs the reader about her lack of understanding through a stretch of IT "The duties of the priesthood was too much for him".

\subsection{Narrator's Presentation of Thought Acts (NRTA)}

The category of NRTA consists of a transitive mental verb or a nominal construction, which is then followed by either a noun phrase or a prepositional phrase containing a noun phrase. Note the example from Joyce's (2011 [1914]) The Boarding House, where Mrs. Mooney reflects on her daughter's romance with Mr. Doran and now thinking to deal it as mature mothers do: "She thought of some mothers" (Dubliners/ The Boarding House 2011 [1914]: 56).

The stretches of NRTA reveal that the type thoughtwhich can represent the noun thought or the verb in the past tense, is key. The same holds for the preposition of, which frequently follows the noun thought. Hence, it can be said that the construction thought of is, in addition to the other constructions identified in my corpus, a diagnostic marker of NRTA, such as in, for instance, "At the thought of the failure of her little surprise and of the two and fourpence she had thrown away for nothing she nearly cried outright." (Clay 2011 [1914]: 93).

It frequently occurs in the middle of the conversation and gives readers a brief insight into the thoughts that motivate the speech of one of the characters, as we have already seen:

As the light failed and his memory began to wander he thought her hand touched his. The shock which had first attacked his stomach was now attacking his nerves. He put on his overcoat and hat quickly and went out. The cold air met him on the threshold; it crept into the sleeves of his coat. When he came to the public-house at Chapelizod Bridge he went in and ordered a hot punch. (Dubliners/A Painful Case 2011 [1914]: 106)

Mr. Duffy considers Mrs. Sinico's behavior abnormal as she expresses her strange feeling in loneliness and the absence of her husband makes Mr. Duffy guilty. Often, we also find mental acts addressed to somebody. NRTA can thus be seen as communicative in that it indicates to the reader what follows next. As such, it also has a prospective function because there is often more than one form of thought presentation in close proximity. NRTA may, for instance, introduce FIT.

\subsection{Narrator's Presentation of Thought (NT)}

Narrator's Presentation of/Reference to Thought (NT) is a category on the thought presentation scale which is newly introduced by Short (2007: 236). It constitutes straightforward thought presentation equivalences of NV and NW and should take their position on the thought presentation scale accordingly (Short 2007: 237). NT does not mention propositional content and does not stress illocutionary force. NT merely highlights the fact that a process of thinking takes place without specifying the contents of this thinking process, such as in stretches like: "Mr. Kernan seemed to be weighing something in his mind." (Dubliners/ Grace 2011 [1914]: 154).

For instance, in the following example from Joyce's (2011 [1914]: 44) Two Gallants, the narrator's ironic comment on the alleged gravity of the situation is created through the exaggerated presentation of Corley's thoughts, on the one hand, and the fact that he is superficially presented as an accommodating and caring man, on the other. The stretch of NT in "His thoughts were running another way" is to underline the extent to which Corley is overwhelmed by the decision he is forced to take. It also creates an atmosphere of silence and somewhat pompously prepares for his spoken utterance about leave-taking:

Lenehan said no more. He did not wish to ruffle his friend's temper, to be sent to the devil and told that his advice was not wanted. A little tact was necessary. But Corley's brow was soon smooth again. His thoughts were running another way." (Two Gallants 2011 [1914]: 44)

The process of thinking without really informing the reader about the content of the thoughts is also exemplified in the following example:

It unnerved him to think that she would be at the supper-table, looking up at him while he spoke with her critical quizzing eyes. Perhaps she would not be sorry to see him fail in his speech. An idea came into his mind and gave him courage. (Dubliners/The Dead 2011 [1914]: 182)

The stretch of NT in "An idea came into his mind and gave him courage" does not inform the reader about the exact content of Gabriel's mental activity as it would have materialized in words; instead, the stretch mainly underlines Gabriel's agitation about making a speech. NT therefore presents just a reference to the thinking process through nouns like thoughts, meditation, reflections and verbs like think. At the same time, NT functions to encapsulate (Sinclair 2004) a thinking process that has previously been presented in FIT. We have already encountered the following example in which thought presentation happens simultaneously to speech presentation, here in $\mathrm{NV}$ : 
Mr. Hynes did not seem to remember at once the piece to which they were alluding, but, after reflecting a while, he said:

'O, that thing is it.... Sure, that's old now.'

(Ivy Day in the Committee Room2011 [1914]: 123)

\subsection{Internal Narration (NI)}

NI is on third place on the scale of thought presentation categories, following NRTA and IT. NI includes the presentation of mental states or a mind state and their changes. These involve cognitive and affective phenomena which do not amount to specific thoughts. Semino and Short (2004: 226) and Toolan (2001: 148) suggest that NI should be seen outside the thought presentation scale, because they present statements that the narrator makes about the inner world of the character. Further, they may be more straightforward minimal presentations of a character's thoughts leading to NT, or they may describe emotional processes or states that endure over a long period.

Short (2007: 236), however, stresses that NI describes an emotion which is related to the speaker's current context in the relevant fictional or non-fictional world. It can also be an emotional reaction triggered by cognitive processing. We often draw on our experience of our body and the physical world to talk about the less palpable domain of our mental and affective experiences.

Verbs and adjectives that normally project NI are, for instance, the nouns fear or shock, the verbs petrify or unhappy, or the adjectives sad or grave. In order to find more reliable semantic clues that would help identify stretches of NI, I ran my corpus of labelled sequences of NI through the semantic tagger of Wmatrix (Rayson 2008). By doing so, I attempted to classify NI diagnostics in a semantically more systematic way.

Often, NI is used in contexts of narrative progression. Emotional processes are also often expressed in line with body movements, reactions or reference to the senses:

Ernest was dead and Harry, who was in the church decorating business, was nearly always down somewhere in the country. Besides, the invariable squabble for money on Saturday nights had begun to weary her unspeakably. She always gave her entire wages - seven shillings - and Harry always sent up what he could but the trouble was to get any money from her father. He said she used to squander the money, that she had no head, that he wasn't going to give her his hard-earned money to throw about the streets, and much more, for he was usually fairly bad on Saturday night. (Dubliners/Eveline 2011 [1914]: 29).

Here the stretch of NI "the invariable squabble for money on Saturday nights had begun to weary her unspeakably" is accompanied by descriptions of how Eveline's trouble to get money from her father. The description of the setting stirs up a deep-seated fear for Eveline being in a fix to run the daily business.

In Joyce's (2011 [1914]) A Painful Case, physical action and body movements are used to describe Mr. Duffy's state of mind after he is known about Mrs. Sinico's death:

Mr. Duffy raised his eyes from the paper and gazed out of his window on the cheerless evening landscape. The river lay quiet beside the empty distillery and from time to time a light appeared in some house on the Lucan road. What an end! The whole narrative of her death revolted him and it revolted him to think that he had ever spoken to her of what he held sacred. The threadbare phrases, the inane expressions of sympathy, the cautious words of a reporter won over to conceal the details of a commonplace vulgar death attacked his stomach. Not merely had she degraded herself; she had degraded him. He saw the squalid tract of her vice, miserable and malodorous. (Dubliners/A Painful Case 2011 [1914]: 105).

This passage abounds in complex presentations of discourse modes, which move between the description of thought to that of speech and back to that of thought. They construe Mr. Duffy's state of mind, both from an intramental and intermental (Palmer 2004: 226) perspective. What construes his feeling is not a description of 'inner speech,' but a description of her body movement as in "Mr. Duffy raised his eyes from the paper" and the narrator's observations that he "could not speak," which allow the reader to infer how much he must be in shock. A description of his moving eyes activates a schema of either fear or devastation which the reader can draw on. This narrative description therefore also contains a description of his state of mind. Palmer (2004: 224) is therefore right to stress that mental states are often accompanied by physical action which can be caused by and emerge from emotions and feelings. 


\section{Image 4.1 the number of occurrences of verb THOUGHT}

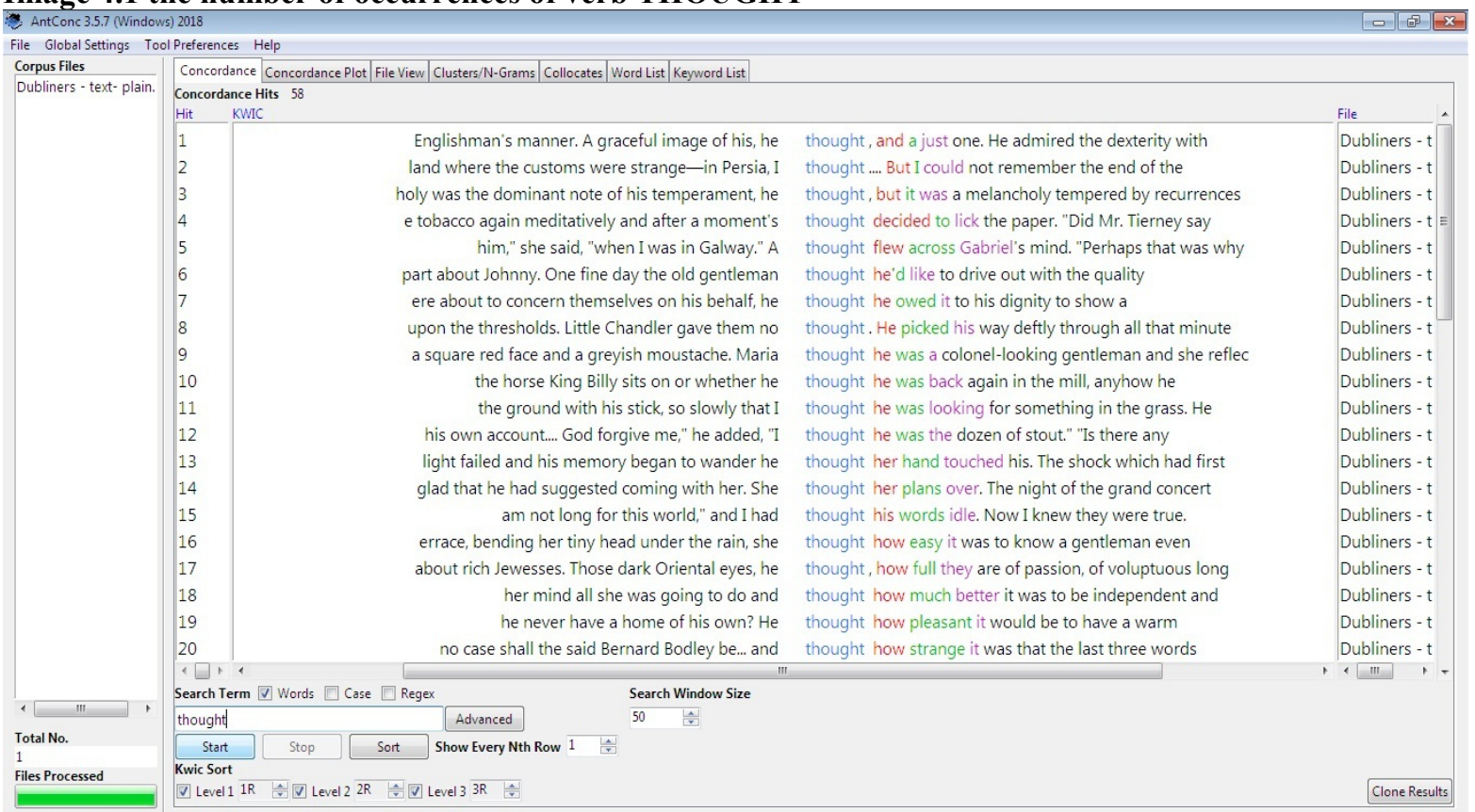

The word 'thought' is the main verb that shows characters' thinking process and it has 58 tags in the corpus.

To conclude, this section has illustrated that it is possible to further categorize passages of NI according to whether they refer to expectations, psychological actions, or positive and negative emotions. It has also illustrated that this report of a state of mind is dialogic and contextual and can serve as both prospecting and encapsulating both physical and mental action.

\section{Conclusion}

Overall, it is found that, of the three modes of presentation, thought presentation is the most frequent and writing presentation the least frequent. All categories of SW\&TP occur in the corpus.

In quantitative terms, the main characteristics of the corpus can be summarized as follows:

- It has more speech presentation than the other two categories in the Dubliners

- It has more DS than the other two categories i.e FIS and IS

- It has more IS than the other two categories i.e FDS and FIS

- It has more NRSA than the other two categories i.e IS and FDS

The corpus has more FIT, and more instances of double-tags. The greatest differences can be found between the selected works. Discourse presentation categories fulfil the function of prospection and encapsulation and mark narrative progression, which - through specific lexico-grammatical choices and the ways these are repetitively dispersed through the texts and in the corpus - shapes the reader's expectations, for instance, as to suspense or surprise. This finding could be obtained through the analysis of the individual incidents of the respective modes of discourse presentation.

\section{References}

Banfield, Anne. 1973. Narrative style and the grammar of direct and indirect speech. Foundations of Language 10: 1-39.

Baynham, Mike. 1996. Direct speech: What's it doing in non-narrative discourse? Journal of Pragmatics 25: 6181.

Baynham, Mike and Stef Slembrouck. 1999. Speech representation and institutional discourse. Text 19.4: 43957. Investigating the presentation of speech, writing and thought in spoken British English

Busse, Beatrix. 2014. (New) historical Stylistics. In The Routledge Handbook of Stylistics, ed. Michael Burke, 101-117. London and New York: Taylor and Francis.

Buttny, Richard. 1997. Reported speech in talking race on campus. Human Communication Research 23.4: 477506.

Clark, Herbert H. and Richard J. Gerrig. 1990. Quotations as demonstrations. Language 66: 764-805.

Cohn, Dorrit. 1978. Transparent minds: Narrative modes for presenting consciousness in fiction. Princeton NJ: Princeton University Press.

Fludernik, Monika. 1993. The fictions of language and the languages of fiction: The linguistic representation of speech and consciousness. London: Routledge. 
Hall, Christopher, Srikant Sarangi and Stef Slembrouck. 1999. Speech representation and the categorization of the client in social work discourse. Text 19.4: 539-70.

Halliday, M. A. K. 1994. An introduction to functional grammar. 2nd edition. London: Edward Arnold.

Holt, Elizabeth. 1999. Just gassing: An analysis of direct reported speech in a conversation between employees of a gas supply company. Text 19.4: 505-

Leech, Geoffrey N. and Michael H. Short. 1981. Style in fiction. London: Longman.

McHale, Brian. 1978. Free indirect discourse: A survey of recent accounts. Poetics and Theory of Literature 3 : 235-87.

Myers, Greg. 1999. Unspoken speech: Hypothetical reported discourse and the rhetoric of everyday talk. Text 19.4: 571-90.

Oakes, Michael. 1998. Statistics for corpus linguistics. Edinburgh: Edinburgh University Press.

Ravotas, Doris and Carol Berkenkotter. 1998. Voices in the text: The uses of reported speech in a psychotherapist's notes and initial assessments. Text 18.2: 211-39.

Semino, Elena and Mick Short. Forthcoming. Corpus stylistics: Speech, writing and thought presentation in a corpus of English writing. London: Routledge.

Semino, Elena, Mick Short and Jonathan Culpeper. 1997. Using a corpus to test and refine a model of speech and thought presentation. Poetics 25: 17-43.

Semino, Elena, Mick Short and Martin Wynne. 1999. Hypothetical words and thoughts in contemporary British narratives. Narrative 73: 307-34. ICAME Journal No. 28

Short, Mick. 1988. Speech presentation, the novel and the press. In W. van Peer (ed.). The taming of the text, 6181. London: Routledge.

Short, Mick. 2003. A corpus-based approach to speech, thought and writing presentation.

Short, Mick, Elena Semino and Jonathan Culpeper. 1996. Using a corpus for stylistics research: Speech and thought presentation. In M. Short and J.

Thomas (eds.). Using corpora in language research, 110-31. London: Longman.

Short, Mick, Elena Semino and Martin Wynne. 2002. Revisiting the notion of faithfulness in discourse presentation using a corpus approach. Languageand Literature 114: 325-55.

Short, Mick, Martin Wynne and Elena Semino. 1999. Reading reports: Discourse presentation in a corpus of narratives, with special reference to news reports. In H. J. Diller and E. O. GertStratmann (eds.). English via variousmedia, 39-66. Heidelberg: Universitätsverlag C. Winter.

Sperberg-McQueen, C. M. and Lou Burnard (eds.). 2001. TEI P4: Guidelines for electronic text encoding and interchange. Oxford-Providence-Charlottesville-Bergen: TEI Consortium.

Thompson, Geoff. 1996. Voices in the text: Discourse perspectives on language reports. Applied Linguistics 174: 501-30.

Wynne, Martin, Mick Short and Elena Semino. 1998. A corpus-based investigation of speech, thought and writing presentation in English narrative texts. 